LUXIÉRNAGA

Eva Gabriela Morales Díaz 


\section{La angustia como necesidad para la conformación de la existencia personal en Sören Kierkegaard}

\section{Introducción}

El título del presente escrito refiere apenas un peldaño en la extensa discusión del significado de uno de los pilares temáticos centrales del pensamiento filosófico, la existencia humana; es, apenas un hueco que deja asomar el rayo de la luz radiante e impoluta proveniente del pensamiento Kierkegaardiano que busca como objeto principal, marcar el rostro claro de la complejidad humana, un camino que solo puede ser recorrido mediante la aclaración de los conceptos que marcan la línea vital de lo posible.

Conceptos como "libertad", “continuidad", "eternidad” son desarrollados y esclarecidos como camino que nos dirige al núcleo del especial pensamiento originario del filósofo danés, la existencia personal u original; es el meollo del asunto existencial a estudiar, dentro del cual, "la angustia" es el objeto central pues solo a través de él se puede llegar a proveer a la persona que lo padece, de un sentido de autoconocimiento, una esfera de interioridad en el cuál se cae en consciencia de la libertad que se posee, y no quedando inhibido en el mismo sentimiento, pues no es una angustia estrecharte ni determinante, sino, más bien, un sentimiento liberador que no utiliza un elemento normativo para cumplir dichos fines, sino que da paso a la creación de una consciencia que delata el máximo potencial, hablando de las dos naturalezas del hombre, la finita y la infinita.

Es entonces una capacidad de la auto creación consciente y por lo tanto se crea y asume la responsabilidad que viene con ella. 
Se habla asimismo de tres momentos o estadios que identifica Kierkegaard en la existencia humana; el estético, el ético y el religioso, cada cual, es más perfecto que el otro; uno puede tener una exigencia pasiva, contemplativa y estética dejándose llevar por los instintos momentáneos; puede ser asimismo un ser ético con una continuidad marcada pero no ser consciente de lo que lo impulsa al desarrollo de sus acciones o uno puede ser y existir en un sentido religioso, siendo un caballero de la fe, tan consciente como irracional; las posibilidades existenciales son tan extensas, por lo que solamente lo infinito puede educar en la finitud, en la existencia personal.

\section{El concepto de la angustia y los estadios vivenciales de Kierkegaard}

Nacido el 05 de mayo de I8I3 en Copenhague, sus padres Mikael Pedersen Kierkegaard y Ane Soren Lund, educaron al pequeño, esbelto y jorobado niño con estabilidad económica y creencias religiosas apegadas al luteranismo protestante de Dinamarca, lo que influyó de gran manera en Soren. Su padre creía firmemente que la vida de su familia estaba bajo un tipo de castigo divino, pues estuvo envuelta en una serie de eventos desafortunados, ya que varios de los hermanos que antecedieron a Soren murieron a temprana edad, esto, por engendrarlos fuera del matrimonio, por lo que su padre se encargaría de que su familia se entregara completamente a una vida religiosa para aminorar la ira divina.

Entrado ya en sus estudios de teología; el joven Kierkegaard en constantes pelas con su padre, por sus imposiciones religiosas, se alejó de estos estudios por un tiempo, prefiriendo los temas filosóficos y literarios; pero, tras la muerte de su progenitor, retoma como tributo su formación en la escuela de Virtud cívica y posteriormente teología en la universidad de Copenhague. 
Encontrándose en el "Siglo de oro"', respecto a las producciones culturales de Dinamarca, Kierkegaard se inicia en los estudios filosóficos y literarios. Graduándose en I84I,y después de dos años, publica su primera gran obra $O$ lo uno o lo otro; en ese mismo año podemos también mencionar Temor y temblor que, junto con El concepto de la angustia, son referentes de las bases que antecedieron al existencialismo, aunque no se puede afirmar que Kierkegaard pertenece a esa corriente porque no la asume como tal, aunque sí sienta la bases de ésta por el énfasis puesto en la noción de existencia y el pensamiento subjetivo. ${ }^{2}$

Otra característica que podemos identificar en Soren es una fe exasperada que no se conforma sólo con explicaciones religiosas, sino que va más allá de la simple obediencia y la hipocrecía de una vida religiosa aparente; bajo estos principios se dedicó constantemente a la crítica de este falso cristianismo, lo que le hizo acreedor a inumerables críticas de la prensa religiósa y atea de la época; incluso siendo víctima de burlas constantes por su apariencia física.

Kierkegaard estaba convencido de que los problemas y maldiciones, que tanto temía su padre, de hecho no existían, pues su vida fue la excepción ya que fue el primero en sobrevivir ante los cinco descesos que le antecedieron, tal oportunidad lo dejó llegar a la adultez; sin embargoel 2 de Octubre de I855 Kierkegaard en un arrebatado debilitamiento cayó al pavimento, entrando en una agonía que el 2 de noviembre de 1855 terminaría con su muerte, cuando tenía apenas 42 años. Sólo así Soren experimentaría las recompensas de las reflexiones de su vida, quizá la más anhelada es la recompensa por la cuál entregóa Regina,ahora no se le regresaria como lo penso; en vida sino con la promesa de pertenecer a un plano mayor; cuando el hombre por un momento deja lo finito para entregarse a lo infinito.

\footnotetext{
1 "El siglo de oro" se refiere a la época de producción cultural de Dinamarca durante la primera mitad del siglo XIX, a pesar de estar en un periodo de incendios y quiebra nacional propiciando una imagen no favorable social y económicamente, la producción artística y literaria fue muy desarrollada, podemos encontrar como principal corriente el romanticismo alemán, mismo que se relaciona a Kierkegaard.

2 Collins, James. (1958). el pensamiento de Kierkegaard (trad. Elena Landázuri), México, Fondo de Cultura Económica, p. 166.
} 


\section{Especialidad en el pensamiento de Kierkegaard}

Para Kierkegaard la filosofía parte del sujeto y no desde una reflexión del universo, tema principal de los estudios de sus contemporáneos, lo que le generó rivalidad con algunos, la más destacada es la que mantuvo con Hegel, en concreto con su dialéctica, a la que critica como alejada y perdida de la esencia humana y también en el concepto de la libertad y voluntad, pues la entiende exsitente en sí y por sí como escencia universal, el hombre posee una volunatd, únicamente formal dictada por el absoluto sométiendose objetivamente al estado como realización temporal y al devenir histórico universal, grande contradicción respecto a nuestro pensador pues los tintes existencialistas de Soren dictan la individualidad y la especificidad del género humano incapaz de encasillase en tesis, antítesis y síntesis. Kierkegaard, en su lugar, introduce una diléctica existencial con el objeto en el sujeto mismo, "Es un ser como contingencia y no como momento de razón absoluta y universal", ${ }^{3}$ es imposible catalogar al ser humano en leyes generales aplicables por el hecho de poseer razón, como punto de referente principal, pues kierkegaard en una de las posturas en las que más insiste a lo lago de todas sus obras, es que cada ser humano posee tintes específicos imposibles de comparar y que mas bien "es objeto del propio individuo, hablando como individuo con un individuo" 4 y no como una pieza universal pues como veremos posteriormente, "la verdad es subjetiva", Kierkegaard fue un pensador revolucionario que cambio el modelo cienentífico aceptado en el modernismo como pieza indispensable de todo estudio y regresa de alguna forma a las antiguas filosofías centradas en el objeto y la interioridad a menudo llamado muy acertadamente como el segundo Sócrates, trayendo a colación una moderna forma de cultivo griego personal y, por lo tanto, existencial.

\footnotetext{
${ }^{3}$ Ibíd., p. 71.

${ }^{4}$ Monrroy, Amalia. (2006). Soren Kierkegaard o la angustia o el concepto Barcelona, la periodic virtual de la seccio clinica de Barcelona, p. 4.
} 
La intención de la filosofía Kierkegariana no es proporcionar un algoritmo fijo para la resolución de los problemas humanos; sino proporcionar una atmósfera interior que permita al individuo volverse a sí mismo, por ello las obras de Kierkegaard se centran en ámbitos correspondientes a la reflexion individual y personal, solitaria y consciente, en el camino; el pensador se dedicó a establecer los conceptos pertenecientes a esta autoreflexión.

Todos estos conflictos biográficos conllevan a una filosofía como reflejo extendido de su vida;y concluyo de la de todo hombre. En la mayoría de sus obras utiliza seudónimos y apodos estrictamente seleccionados, bajo reflexiones que pueden provenir de distintos sujetos,"los autores son personajes encubiertos con un pseudónimo, representantes individualizados de estas diferentes soluciones al problema de la vida"5, a los problemas existenciales.

No por nada las distintas interpretaciones del pensamiento de Soren dan demasiado énfasis a las circuntancias de su biografía y en especial las afectivas que mantenia con Regina Olsen, argumentando que su pensamiento es resultado del conflicto interior que le provocaron los sentimientos encarnados por su especial relación con la señorita, reflejados en su literatura, especialmente en tres fuentes; $O$ lo uno o lo otro, Temor y temblor, y el famoso Diario de un seductor, por medio de estas obras es que la historia romántica de Kierkegaard se vuelve una de las mas ricas y registradas en la filosofía podemos decir que también un movil para su interes y relevancia atemporales, pues por medio de sus obras se explica sus desiciones personales; aunque no podemos reducir su filsofía a estas razones y estructura, pues al igual que su temprana exposición al terror, el pecado y la angustia influida por su padre son razones por las que el pensamiento de Kierkegaard es tan particular.

Pues estos le ayudaron a consolidarse como una figura original y revolucionaria respecto a su manera de reflexionar y por tanto, de escribir en especial, se destacan sus tintes poéticos que correspondientes a su época retoma del romanticismo, más que el

${ }^{5}$ J. Collins, Op. Cit., p. 51. 
academicismo estricto de los estudios teológicos tradicionales esta diferiencia le permitía la crecación de un espacio de reflexión humana, pregonada a lo largo de toda su vida; la filosofía kierkegaariana posee diversidad de elementos tanto conceptuales como literarios que le proporcionan un estilo único.

\section{El concepto de la angustia}

Kierkegaard hace una diferenciación entre la vida y la existencia, nos dice que los animales simplemente están, es decir, viven sin ninguna consecuencia o posibilidad de cambio existencia para él la palabra existencia no posee un sentido compartido por el lenguaje común, la palabra existir únicamente puede cumplirse dentro del modelo especifico del hombre, pues posee consciencia de un pasado y un futuro potencial; los seres vivos, como los animales y las plantas solo están o duran, el hombre también dura pero como condición para existir.

La capacidad de elección constituye lo que se es, entre la inmensa posibilidad de posibilidades, el ser humano es su propio creador, va construyéndose a partir del lienzo blanco en que solo vive, por lo que la primera decisión del ser humano es elegirse a sí mismo para existir, desgraciadamente muchos de los hombres no generan un espacio de reflexión y separación del yo por lo que no se puede decir que existen, por ello experimentar lo que Kierkegaard llama la angustia es fundamental, ya que "la angustia es inerte a la situación del hombre en el mundo; como existencia subjetiva de su naturaleza".

Pero entonces, se preguntará el lector, ¿Qué es la angustia? la angustia había sido signifcada etimológicamente en las lenguas germánicas y griegas como angest, que se traduce como (miedo o molestar) y eng (angosto, estrechamiento) el sentido frecuente ante una amenaza que se manifiesta generalmete con una senación de presión

\footnotetext{
${ }^{6}$ Ibid., p. 12.

${ }^{7}$ Cañas, José. (2003). Soren Aabye Kierkegaard entre la inmediatez y la relación, Madrid, Trotta, p. 80.
} 
en el pecho, de ahí su nombre; en la modernidad se retomó el concepto aunado a la razón con los ilustrados y con el sentimiento con los románticos, teniendo como precursor a Kierkegard en donde el término comenzó a tener relación directa con el hombre y su libertad, Heidegger tendrá en cuenta estas reflexiones remitiendose al concepto (como la condición natural y el desazaciego de la forma de estar ante el mundo $)^{8}$, los existencialistas tambén reformularon el concepto; Sartre (la angustia es el modo de la libertad como conciencia de ser) $)^{9}$ entre muchos otros estudios que dan luz a este fenómeno humano.

Pues bien, Kierkegaard hace resignificar este concepto como ningun otro pensador "la relación angustia/estrechez es menos determinante que la relación de la angustia con la nada y la posibilidad". ${ }^{10}$

Primero debemos entender que existe una separación entre el miedo, la angustia y la desesperación, Siguinedo a Kierkegaard, el miedo (Furcht) es la respuesta o el terror a algo concreto y fijo, posibilidad de algo; mientras que la angustia es la reacción a la libertad, a una extensa infinidad de posibilidad eso, mejor dicho, la posibilidad de las posibilidades; el tercer concepto; la desesperación, se describe como el estado de quien ya no espera nada, ante una posibilidad sin posibilidades en relación subjetiva. ${ }^{\text {II }}$

Tanto la desesperación como la angustia son descritos por Kierkegaard en el marco de un exhaustivo estudio del pecado original (pecado hereditario), en donde, en un primer momento, se tenía ignorancia de lo que era el bien, el mal y sus consecuencias, por lo que, tras el pecado, la angustia es un sentimiento que viene a ser ese vuelco a una realidad que afirma el libre albedrío, aunque no se refiere al clásico concepto donde se puede elegir entre múltiples opciones ofrecidas por el

\footnotetext{
${ }^{8}$ Bueno. Noelia. (2010). "el futuro y la angustia", en Daimón revista internacional de filosofía, 3, p. 4.

${ }^{9}$ Ibíd., p.6.

${ }^{10}$ Schelling, Frederich. (2004). Investigaciones filosoficas sobre la escencia humana: libertad humana y los objetos con ella relacionados (trad. C.y L. ), Barcelona,Antropos $4^{\circ}$ ed., p.106.

${ }^{11}$ Diccionario de los intraducibles. (2018). "Vocabulario de las filosofías occidentales", 9 (trad. Barbara Cassini) s.l., siglo veintiuno, tomo 1, p. 918.
} 
razonamiento practico; sin posibilidad de reflexión, sino que se centra más bien en la inmediatez de la segunda naturaleza humana; la espiritual "alcanzada por la insatisfacción de la propia fuerza interior y no por el razonamiento inmediato escapando de lo estratégico (calculado y programado por la manipulación objetiva)" 12 , sino como el yo responsable de sus actos que está frente a Dios. En las palabras del propio Kierkegaard "la desesperación se condensa en proporción a la consciencia del yo; pero el yo se condensa en proporción a su medida y, cuando la medida es Dios, infinitamente, el yo aumenta con el yo "13 por este primer pecado también surgió la posibilidad de la libertad al no condenarnos a una existencia simple y cómoda sino posible, la angustia de no entender la prohibición y con ello la posibilidad; ésta separación de la vida individual del ser humano convierte a la angustia en más que una emoción, una vivencia que no puede sino solo ser experimentada por sí mismo, en ese sentido es la situación más solitaria que puede haber, además de esto el pecado original cambio, según Kierkegaard, el rumbo de la existencia y vida de los hombres que desde ese acontecimiento están condenados por la libertad de ir de lo posible a lo posible.

Lo acongoja porque pone ante los ojos de su imaginación todo lo que puede llegar a suceder en el futuro. La posibilidad pesa más que la realidad porque la multiplica: conocer la realidad es haberse enfrentado con una sola de las posibilidades, la que se ha actualizado. Enfrentarse con la posibilidad es angustioso porque pone en contacto con la infinitud. ${ }^{14}$

La angustia también se puede entender en dos consecuencias o afecciones, tanto en el nivel de lo que se siente y de lo que se concibe, es pues una categoría del espíritu que aparece cuando surge la posibilidad, como menciona José García "la angustia es como la vibración del espíritu humano ante la llamada de la responsabilidad eterna en la anticipación y preparación de la misma libertad”, ${ }_{15}$ pues al relacionar el sentimiento de

\footnotetext{
${ }^{12}$ Benetti J. María. (2005). La posibilidad necesaria de la libertad: un análisis del pensamiento de Soren Kierkegaard, España, universidad de Navarra cuadernos de anuario filosófico, p.8.

${ }^{13}$ Kierkegaard. Soren. (2002). Tratado de la desesperación, (trad. Carlos Liacho), Madrid, Trotta, p. 117.

14 N. Bueno, art. cit., p.1.

15 García, José. (2010). "Kierkegaard: la sociedad y la angustia del individuo singular", en Revista La mirada kierkegaariana, 1, p. 6.
} 
la angustia con las posibilidades, también queda unida al futuro, con la acción "toma decisiones relativas a las propias acciones y en el fondo un movimiento de la voluntad que impulsa el actuar de una manera o de otra" ${ }^{16}$

Esta concepción se traslada no sólo a una vida religiosa, que era el motivo principal por el cual Soren introduce estos conceptos, pues esta desesperación permite el acercamiento a una vida religiosa, pero, lo que nos interesa más bien es su relación con la libertad, la cual puede transmutar a otros aspectos de la vida, incluso haciendo alusión a nuestra contemporaneidad, que más que en otras épocas es apremiante.

Kierkegaard dirá que la libertad es inerte a la naturaleza, pero también como medida para la creación humana es una opción; es la continuidad de una decisión que el hombre afirma por su existencia y también por sus distintas elecciones, pues el ser humano puede decidir si existe o no.

"La angustia y la desesperación develan la libertad de la infinitud de las posibilidades de la existencia, las posibilidades de la libertad humana respecto a la nada o respecto de sí mismo". ${ }^{17}$ Notemos esta infinita brecha en cuyos extremos está la nada y la infinitud, ésto es lo que conforma la libertad y la angustia, una infinita sensación de infinitas posibilidades, buenas o malas; resultan ser igualmente probables, esta naturaleza de la libertad circunscrita al hombre responde a la doble naturaleza del hombre lo finito y lo infinito; del tiempo y la eternidad, "la libertad da un inicio absoluto, la absolutidad inicia en nucleo sibjetivo y se ubica en ese punto desde donde se puede levantar un mundo eterno". ${ }^{18}$

La experiencia de la angustia permitirá al hombre la interiorización de una vida racional, no sólo respecto de sí mismo, sino también de lo que puede llegar a ser, como potencia Aristotélica; siguiendo a Cañas, podemos decir que "La angustia es como un vértigo frente al abismo que separa lo que uno es y aquello que puede llegar

\footnotetext{
${ }^{16}$ N. Bueno, art. cit., p.3.

17 J. Cañas, Op. Cit., p. 78.

${ }^{18}$ M. Benetti, Op. Cit., p. 43.
} 
a ser" ${ }^{19}$, claro está, de una manera totalmente consciente,nadie puede escapar de la angustia pues es un sentimiento que apoya todasnuestras desiciones.

La angustia la entenderemos, en consecuencia, integrada en dos aspectos principales como existencia (creación) y como escencia (inherte a la naturaleza humana), ${ }^{20}$ es una particularidad común a todos.

He aquí el punto de intriga ¿Qué haremos con esta libertad? pues en este juego entra también la responsabilidad continua de cada persona, Soren se encuentra más que seguro de que ésta experiencia de la angustia incrementa la posibilidad de la perfección del hombre y de su vida, pues ahí reside su posibilidad de elección y creación, esta cuestión nos dice Kierkegaard en temor y temblor no se puede tomar a la ligera, pues, la angustia es capaz de condenar a una persona al impomnio perpetuo , sin embargo sin esta angustia no se es lo que es.

Como se mencionó al principio, el concepto de la angustia es muy importante para Kierkegaard ya que " la angustia no tiene su lugar propio en el terreno del concepto sino en una nota distintiva del ser humano, la experiencia decisiva en la vida de un hombre", ${ }^{21}$ de esta manera se genera o no la existencia de los humanos.

\section{El Estadio estético, ético y religioso}

Por medio de la filosofía de Kierkegaard sobre el cuestionamiento de lo que forma la existencia humana da lugar a discusión, donde el hombre tiene que encontrar el sentido de su existencia, esta pertenencia o extrañeza a lo vivencial delimita y delinea el comportamiento del hombre no sólo respecto de sí mismo, sino con los otros, aunque de una manera menos agresiva que respecto de la relación personal.

\footnotetext{
19. Cañas., Op. Cit., p 52.

${ }^{20}$ Rojas, Fernanda. (2016). "la angustia un camino del hombre hacia lo divino." En Ideas y valores 65, sup, N. 2., p. 137-154.

${ }^{21}$ A., Monrroy, Op. Cit., p. 4.
} 
"la angustia, como estado, psicológico manifiesta el estado abierto del ser humano, la indeterminación del yo, la posibilidad de elegir determinaciones fundamentales respecto de su existencia”. ${ }^{22}$ Kierkegaard lo utiliza para ilustrar la riqueza existencial que hay en cada ser humano.

Esta conformidad de experimentación de los distintos conceptos que apelan a la existencia, dígase el terror, la angustia; la desesperación, cuyos influjos acompañan a las decisiones de la vida de los humanos pueden a llevarnos, dice Kierkegaard, a tres alternativas de estadios de vida, a saber: estético, ético y religioso. Estos estadios son también conocidos como momentos “øjeblik” componen una dimensión existencial hecha por las decisiones del hombre.

Estadio estético: la persona apoya su existencia a través del sentido de la vida como construcción de su propio ser, el hombre en este estadio busca el placer y escapar del dolor, se apega al instante; esto lo lleva a distintas situaciones guiado por cual le dará más placer, cambiando a cada instante y como consecuencia impidiendo su crecimiento estabilidad y creación de proyectos a largo plazo. Se desarrolla por la necesidad y no por la libertad que Kierkegaard sitúa como referente directo encarnado en la figura del Don Juan. El placer es un sentimiento muy fuerte, pero también momentáneo; semejante a la niebla de la mañana; esa nube espesa que impide la vista, desaparece las cosas, incluso las más cercanas; pero a medida que pasa el tiempo, esa espesa y gigantesca nube se difuma, hasta quedar inexistente, ni siquiera un recuerdo fijo de su gloria; entonces esperamos al siguiente día para poder contemplarla, pero ¿Quién nos asegura que de verdad estará ahí?

En este sentido el hombre está sujeto a la inmediatez de las sensaciones que experimenta ya sea provenientes de sí mismo o incluso externas a él estas posibilidades estéticas, que se muestran tan encantadoras y livianas, pertenecen al plano de lo imaginario, nunca se está conforme con lo que se es, pues está sujeta a la dialéctica de

\footnotetext{
${ }^{22}$ Guerrero, Luis. (2017). ¿Qué significa existir? Ensayos sobre la filosofía de Soren Kierkegaard, Roma, Siek if press,
} p. 54 . 
lo exterior y condenada a una repetición existencial del absurdo, al final estas sensaciones son fugaces y terminan hastiando al ser humano; por lo que este sentimiento, en última instancia, lleva inevitablemente a la desesperación, el ser frente a la nada, esto según Kierkegaard nos permite llegar al estadio ético, que se menciona a continuación.

Estadio ético: el hombre está consciente del bien y del mal, esto lo lleva a actuar acorde a normas y reglas de la vida social, para bien ya no únicamente de sí mismo, sino de un todo (universalmente) es decir, busca fundamentar y realizar su yo a través de la mediación de la racionalidad, por ello la individualidad queda relegada por la autonomía del deber, aunque se hace con sus opciones libres. Podemos encontrar en él planes y decisiones que serán fijas, no sobre la indecisión de los placeres, sino de "o lo uno o lo otro" ${ }^{23}$, haciéndolo continuo y reafirmando sus decisiones, viviéndolas día con día. Kierkegaard retoma a la figura del matrimonio como ejemplo de este estadio, pues se asume una éticidad en la vida cotidiana, es la identificación de ciertas limitaciones que se aceptan al ser parte de él.

"La continuidad que carcteriza la cohesión de la vida ética de acuerdo con las exigencias de la realidad social de la vida viene a evitar la disolución y las tonalidades afectivas momentaneas de los hombres". ${ }^{24}$ Está continuidad de lo ético realiza un proyecto que se extinede no sólo al individuo, sino tambien a su familia, al trabajo y por ende a la sociedad, de igual manera la existencia ética de los otros se manifiesta en conjunto lo que es considerado como sociedad.

Cabe mencionar que estos dos estadios, el estético, y el ético pueden coexistir en un mismo espacio/tiempo, "en el acercamiento de ambos caminos se descubre elementos genuinos de nuestra naturaleza", ${ }^{25}$ pero estos estadios tan opuestos pueden llevarnos a la desintegración de la vida personal y social. Aunque pareciera que el

23 Frost R. (04 agosto 2010) notas a pie de camino. recuperado de 03 abril 2020, de https://notasalpiedelcamino.blogspot.com

${ }^{24}$ F., Shelling, Op. Cit., p. 306.

${ }^{25}$ J, Collins, Op. Cit., p. 89. 
estadio ético es mucho mas recomendable que el estético, el situarse en él no corresponde a la mejor de las existencias, según Soren; por ello es tan vital el tercer estadio.

Estadio religioso: el hombre vive delante de Dios, cambiando su desesperación por la esperanza y la angustia por confianza, se ha entregado a él, y sabe que le debe obdecer, aunque esto llegue a contradecir la ley humana, él se entrega sin siquiera saber la profundidad de lo que se le pide (salto de fe).En este sentido el salto al estadio religioso es lo más angustinante, porque sobrepasa la comprension a luz de la razón humana.

Se trata pues en este estadio de reafirmar la existencia única, por ello ésta acción se realiza de manera individual y aislada, esta soledad va ligada al hecho de mantener una relación directa con Dios, en consecuencia lo lleva a obrar con amor, no por necesidad (estadio estético) o deber (estadio ético).Es el más puro de los estadios.

Podemos entender la preferencia de Kierkegaard respecto de los estadios vivenciale y es que; de alguna manera se veia como un elegido; sus descripciones en temor y temblor que relata la famosa historia bíblica de Abraham e Issac ilustra mucho el sentimiento compartido también por Kierkegaard, el entregar su mas fuerte inclinación al mundo terreno que era Regine; con la promesa de que si tenia la suficiente fe, su amada le sería devuelta tal como Isac le fue devuelto a su amado padre, por la reverencia considerada irracional a Dios; de esta manera Kierkegaard ilustra casi el único riesgo de este estadio, el correcto entendimiento; porque ¿Cómo se puede estar seguro de entender lo que Dios me manda?, en temor y temblor Soren nos dice que el dialogo con Dios es en realidad un monologo. ${ }^{26}$

Por ello la figura de El caballero de la fe adquiere un nivel mucho mas superior que el estético y ético, pues solo puede confiar en él mismo no en las cosas y sensaciones(estético) ni en las demas personas o estatutos, ni siquiera en su logica

${ }^{26}$ Kierkegaard Soren. (1843). Temor y temblor (Trad. Vicente Simón Merchán) s.l., epublibre, p. 26. 
(ético) sino que se encuentra en la soledad mas infinita que puede haber, la palabra danesa Afgaegtelse, que significa peligro, angustia o duda, es un estado en el que el hombre se encuentra con el umbral de lo divino y el misterio del absoluto, este es el sentiniento concreto que sufre el caballero de la fe, cobrando con ello, en palabras de Kierkegaard: "una existencia superior".

Las categorías de Soren corresponden a un tipo de escalera, semejante a la que construye Comte, en donde cada estadio que se superaba serviría de avance a la consideración del segundo y, posteriormente, con éste se afirmaba el tercero, llevando todas las correciones y bases para la fundamentación de un estadio nuevo correspondiente al lugar que ocupaban, ascendente, corresponde en ambas explicaciones, tanto la de Kierkegaard como la de Comte, una relaciòn de ascendencia/complejidad, pero a diferencia de los estadios de Comte este orden estaba condicionado a la complejidad del pensamiento (lógico- cientifico) encontramos en kierkegaard los modos de ser, aunque estos no correspondan totalmente a la racionaliad; suponen una mayor perfección en cuanto a que procuran acercarse a algo más abstracto y perfecto, como lo es la exitencia o en su defecto Dios, el sentimiento religioso.

Se debe hacer una distinción importante, hablar de este estadio no se debe confundir con la religiosidad aparente que otorga la institucionalización de la fe, mediante un culto mediado por la comodidad de la apariencia, pues ésta comodidad sintetiza los elementos estéticos, éticos y religiosos a costa de ocultar su yo a sus propios ojos, nunca cayo en cuenta, ni sintió la impresión del hecho de la existencia de Dios y de él mismo, una gracia infinita que no se puede alcanzar sin pasar por la desesperación. ${ }^{27}$ Kierkegaard aboga no por la cristiandad, sino por el cristianismo; pues este último no conlleva un estado de paz y tranquilidad sino que provoca, en el

\footnotetext{
27 Martínez, Luis. (1993). Kierkegaard los límites de la razón en la existencia humana, México: sociedad iberoamericana de estudios Kierkegaarianos, p. 2015.
} 
hombre, una inmensa incomodidad pues el hombre se encuentra cara a cara con la angustia de existir es temor y temblor.

Conforme a éstos estadios de vida también está el grado de esfuerzo que se pone en cada una de ellos; "un modo de concebir y realizar la propia existencia, una actitud fundamental o nivel de realidad en el que plantea y orienta al hombre a su existencia, y cada tipo de actitud ante la vida presenta una lógica peculiar, una articulación interna que engrana los diversos mometos de la vida humana" 28 es decir, que al pasar de estadio se tiene la responsabilidad de continuar avanzando, si se está en el estético o en el ético; en el caso del estadio religioso se deberá cuidar permanecer en él y no retroceder, para ello también la angustia viene a ser una herramienta que ayuda a su preservación.

pues la consciencia y el estado psicológico del primer pecado permanecen mientras, que al mismo tiempo, ésta historicidad corresponde a y para sí mismo, como responsable de sus actos logra despertar en él la consciencia máxima para valorar la verdad, "tal impulso le permite dar el salto constantemente a lo valioso" 29.

De manera que podemos hacer una analogía respecto al mito de la caverna de Platón, aquél hombre liberado de las ataduras y del mundo de las sombras, que ha contempado el sol en toda su gloria, no desea volver más a aquel mundo que dejó atrás, aunque con ello deje todo lo que conoce para aventurarse a un mundo nuevo, a uno mejor. Esto es para Kierkegaard el estadio religioso, una elevación.

\section{La importancia del yo y la existencia original en Kierkegaard}

La necesidad de conocerse a sí mismo es una característica importante en el ser humano y ha estado presente como consecuencia de ello en las concepciones del pensamiento, ya mencionamos que Kierkegaard es tomado como precursor del

\footnotetext{
${ }^{28}$ J. Cañas, Op. Cit., p. 65.

${ }^{29}$ Ibíd., p. 110.
} 
existencialismo pues se pregunta y cuestiona acerca de la existencia, la libertad y otros términos relacionados, a la existencia habrá que añadirle un predicado esencial en Kierkegaard; la originalidad.

Uno de los objetivos ocultos en las obras del filósofo danés implica que la existencia da una posibilidad de perfeccionamiento y creación y que una existencia no original se encuentra en el peldaño más primitivo y natural del hombre, estas cuestiones nos llevan a plantearnos en la actualidad con mayor ímpetu, las secuelas de la masificación y alienación que son consecuentemente los enemigos acérrimos de la existencia original.

Como dice Luis Guerra "el problema no es el contacto con los demás, sino que esta relación no este presidida por una idea clara sobre sí mismo” ${ }^{30}$ el sí mismo es un término que aparece constantemente en las obras de Kierkegaard, especialmente Temor y temblor, en la que menciona, a través de historias, las decisiones que toma el caballero de la fe, el esteta y el ético.

Esto haciendo referencia a los distintos estadios vivenciales mencionados anteriormente, el ser es el punto crucial de estos estudios pues el sí mismo original no debe, en ningún momento, perderse ni cambiar al estar en contacto con los otros; en el estadio en el que se genera con mayor éxito esta comprensión es en el religioso, pues el caballero de la fe, podemos observar, que ante todo tiene claro que solo puede confiar en sí mismo y que las existencias que necesitan aprobación por el resto denotan la incomprensión de sí mismo así como un grado de existencia distinto.

La existencia no original también se denomina como la enfermedad mortal en Kierkegaard; es aquel padecimiento sordo que no permite la comprensión real del mal; la falsa comodidad y pasividad de la existencia ajena y repetida el desesperado que se encuentra en esta situación debe decidir entonces que hacer de sí mismo "La desesperación puede adquirir asimismo dos figuras: el desesperado inconsciente de

\footnotetext{
${ }^{30}$ L. Guerrero, Op. Cit., p. 29.
} 
tener un yo; el despertado que no quiere ser él mismo, y aquel que no quiere ser él mismo, y aquel que quiere serlo" ${ }^{31}$ He aquí el problema conjunto, la irresponsabilidad en adoptar una posicion del yo, de la exitencia del individuo. Kierkegaard describe la situación del desesperado como sentir en el más profundo centro de su alma una cierta inquietud no querer ser él mismo

Para salir de esta situación Kierkegaard se apoya en su concepto central; la angustia.

Como ya mencionamos "la infinitud ante la que la angustia sitúa al hombre tiene forma de posibilidad", ${ }^{32}$ decimos que manifiesta la libertad que hay en el hombre de elegir su existencia y por lo tanto sus acciones, la angustia es un concepto que dota de posibilidades existenciales, tal como la vivió el propio pensador, pues solo a través de ella se puede llegar a la consciencia de sí mismo, la soledad como principio catártico y concreto ante la propia existencia que genera la angustia permite la atmosfera para el autoconocimiento que es necesario para la acción.

El domino de la angustia sin rozar en extremos fatales, con ese efecto catártico nos lleva a un saber supremo, no es el caso por ejemplo de la epojé de olvidarse de la realidad incluso de uno mismo, sino que en general la afirmación de la existencia y libertad de sí mismo.

"la angustia termina donde empieza la realidad y prepara al hombre para ella" ${ }^{33}$, solo la posibilidad puede educar en la finitud, por lo que la angustia a pesar de contemplar aspectos no necesariamente que se trasladan al presente, sino como posibilidades Kierkegaarianas contingentes nos llevan a una mejor consciencia de nuestros actos

\footnotetext{
${ }^{31}$ Kierkegaard. Soren. (2003). la enfermedad mortal, (trad. Demetrio Gutiérrez Rivero), Madrid, Trotta, p. 14.

${ }^{32}$ N. Bueno, Op. Cit., p. 23.

${ }^{33}$ Ibídem.
} 
De manera que "sentimos angustia porque sentimos encima las poibildades de la elección latentes de la existncia", ${ }^{34}$ lo que nos lleva, irremediablemente, a una posición reflexiva y regresiva al yo. De manera que la angustia es una herramienta natural que nos ayuda a ser concientes de nuestra existencia como elemento necesario, pero es también importante tomarle aprecio y fortalecer este sentimiento pues, segun Kierkegaard, cuanto mas perfecto sería el hombre cuanto mayor sea su posibilidad de angustia.

El hombre actúa, se angustia, porque de esta manera es la naturaleza de las cosas que lo rodean, cambiantes; siendo el hombre parte de esta naturaleza, debe por lo tanto ser más consciente de ellas, pero teniendo en cuenta el gran apoyo que posee por tener su segunda naturaleza, la infinita.

La angustia como cruce en el interior de la persona entre la determinación natural o animal y la determinación espiritual, nos dice Kierkegaard existe una verdad subjetiva a la que el sujeto debe acceder pues corresponde a cada individuo construir y hacer su propio yo, tal como indica Kierkegaard los estadios vivenciales, la angustia comporta un aspecto importante a la hora de avanzar a un lugar de responsabilidad existencial; la soledad es necesaria para descubrir nuestra interioridad, sin ella estaríamos condenados a perdernos entre la masa de estímulos externos (estadio estético) del cual de todas las maneras posibles nos conduce a un hastío y aburrimiento, el encontrarse consigo es tomar la responsabilidad y el necesario recogimiento espiritual.

La angustia, como estado psicológico, manifiesta el estado objetivo del ser humano, la indeterminación del yo, la posibilidad de elegir determinaciones fundamentales respecto de la existencia propia se trata entonces de un aspecto que es también muy importante en Kierkegaard, la continuidad.

${ }^{34}$ J. Cañas, Op. Cit., p. 86. 
"El equilibrio entre la continuidad y el aislamiento la personalidad se forma por la elección de sí mismo, que permite que el individuo devenga responsable de sus propios actos", ${ }^{35}$ como ya vimos la continuidad ayuda a salir de la existencia estética pues la continuidad solo se puede generar en relación con los actos que son conscientes y no momentáneos, es una decisión sobre sí mismo que tiene valor de origen en cuanto precede a la libertad de elección.

La angustia, en este sentido, permite la continuidad como el aislamiento y separación de la personalidad como una existencia única que se remite a su segunda naturaleza lo infinito (Evlghead) en cuanto a posibilidad de creación y de indeterminación; desde que Kierkegaard explica el concepto de la angustia se remite al pecado hereditario como una capacidad de acto y, al mismo tiempo, a una imposible determinación única en el ser humano, pues tanto el bien como el mal surgen del mismo salto, ${ }^{36}$ por lo que separa desde un principio la existencia de la durabilidad o vida respecto de los seres humanos y otro tipo de seres; por que el hombre en este sentido posee una naturaleza cuya única determinación es ser indeterminado.

Pero entonces por qué Kierkegaard apostará, por una existencia original a una existencia más baja si de todas maneras ambas son posibilidades situadas entre la brecha de la nada y la eternidad, en este punto surge un cuestionamiento importante ¿la existencia pasiva acaso compone una existencia en si misma? Kierkegaard responderá que sí, pero que esta se sitúa en el límite de lo natural, que poco falta para ser el mismo de los animales, solo que en esta cuestión, al igual que en el estadio estético, el hombre si está eligiendo las otras cosa, las sensaciones y placeres, tal existencia desperdicia de alguna manera las posibilidades con las que se cuenta, Kierkegaard prefiere tomar esta posibilidad y la potencia en la existencia más

\footnotetext{
35 Vocabulario de las filosofías occidentales, Op. Cit., p. 1175.

${ }^{36}$ Por ello el estudio de Kierkegaard también se utiliza para describir el pecado, pero también de la existencia de lo malo y lo demoniaco.
} 
incómoda, la elección de sí que se encuentra justo en el extremo, pues confiere a la persona su valor eterno, que da como consecuencia el máximo de pasión. ${ }^{37}$

La existencia original implica un esfuerzo mayor, pero también un resultado mucho más grande, al igual que el razonamiento por el cual Kierkegaard apoyaba la cristiandad, pero no el cristianismo, argumentando que en la institucionalización de la fe ni la existencia ni la conciencia se logran desarrollar de manera plena, pues estas se encentran frenadas por decisiones y consolaciones externas que de alguna manera hacen que las repercusiones de nuestros actos sean menos violentas y que puedan ser "salvadas" de sus consecuencias, no es otra cosa sino eufemismos justificatorios para nuestro comportamiento.

Kierkegaard a través del concepto de la angustia y la reflexión de los estadios vivenciales lo que nos trata de decir es que la responsabilidad real de la existencia que solo en medida de la angustia se hace consciente pues ésta contempla lo que se hace, pero también lo que no; lo que es real y las posibilidades de ser, nuevamente, la educación para lo finito solo puede provenir de lo infinito.

\section{Conclusión}

Sin duda, el pensamiento de Kierkegaard es muy complejo, quedando mucho que agregar al estudio de la existencia humana, si se me pregunta porque considero tan esencial las concepciones y conceptos que introduce este filosofo pre existencialista, respondería mencionado de ante mano la capacidad con la cual es capaz de identificar estos conceptos que realmente se aplican a cada ser humano, pero que no lo hacen ser, como los otros humanos; es uno de los pensamientos individualistas más marcados que existen que aportó en su tiempo, y aun, en el nuestro, una discusión fresca y anti

\footnotetext{
${ }^{37}$ Vocabulario de las filosofías occidentales. Op. Cit., p. 515.
} 
determínate de la personalidad, un giro envolvente a las características del ser humano, sus padecimientos y su más allá.

Lo que es el hombre cuando está consigo mismo, la existencia original es el resultado del autoconocimiento, éste a su vez, se da en la esfera de la reflexión individual y, que más singular que la angustia; este estudio se propuso reflexionar acerca de dichos conceptos existenciales para develar el núcleo de la filosofía de Kierkegaard, una meta que creo cumplida, concluyendo que la existencia original es el resultado de un cumulo de padecimientos humanos que lo llevan a dar los primeros pasos a una decisión existencial, elegirse a sí mismos. Y que concluyen con un salto a la propia originalidad. 